\title{
ON TWO SPECIMENS OF THE GENUS ENDOPACHYS FROM THE PERSIAN GULF
}

\author{
BY \\ SYDNEY J. HICKSON \\ Professor of Zoology in the Victoria University of Manchester.
}

(With 2 Textfigures)

The genus Endopachys was founded by Lonsdale (1845) for some fossils from the Eocene of Alabama and according to MILNE EDWARDS and HAIME, these fossils belong to the same species as those previously described by Lea (1833) under the name Turbinolia Maclurii.

Another species, Endopachys Grayi was described by the French authors from a specimen in the collection of the British Museum, and although there is, unfortunately, no record of the locality from which it was obtained it is regarded as recent.

VAUGHAN (1900) has described three new fossil species of the genus from Eocene deposits from Alabama and other localities in the United States (E. lonsdalei, E. shaleri and E. minutum) and a recent species (1907) from 52-112 fathoms off Oahu in the Hawaiian Archipelago (E. oahense).

The same author also records the existence of a recent specimen of the genus Endopachys, in the U. S. National Museum, that was obtained in 39 fathoms from the Gulf of California (loc. cit. p. 24 foot-note).

I am indebted to Dr. C. J. VAN DER HORST for the information that three specimens were obtained by the Siboga Expedition in the Malay Archipelago. One specimen (E. Grayi) off Waigeu in 141 metres, another of the same species off the coast of Flores in 40 metres and a third juvenile specimen from the same locality.

From the preservation of the soft parts of these corals it is evident that they were living corals when captured.

In the British Museum there are two specimens of E. Grayi. The Type specimen (locality?) is not very compressed and the wings narrow. The septa do not reach far into the cavity and consequently the columella is more exposed than in other specimens. It is evidently water-worn, the surface being almost smooth. It is difficult, therefore, to determine how far the peculiarities of the septa are due to post-mortem breakage.

- The second specimen (from Manilla) is large and well preserved, but one side appears to be distorted in growth with the result that the septa of that side are longer than the corresponding septa of the other side and their free edges do not fuse in the manner characteristic of the specimens.

In the collection of the Manchester Museum I have found a specimen of the same genus, one of the many valuable donations to the Museum of the late Mr. R. D. DARBISHIRE, which is labelled Endopachys grayi? Loc. China Seas?

Two specimens of $E$. Grayi were found by Mr. TownsENd in 55 fathoms off Massandam in the Persian Gulf. They are both incomplete and, from the growth of Polytrema on the edge of the calyx, had probably died some time before they were brought up in the dredge. However, they are in a better state of preservation than the Darbishire specimen. 
The genus Endopachys appears to be very well defined and there is no difficulty in distinguishing it from other corals of the family to which it belongs.

It is solitary, free, fan-shaped like the Turbinoliid genus Flabellum and perforate.

Although it is strictly solitary, it can reproduce by marginal gemmation. One specimen (Fig. 1) has been found in which the bud is still attached to the margin of the calyx, but there is no evidence that this process of gemmation ever leads to the formation of a colony. It is remarkable that no evidence has yet been produced of this process of gemmation in the numerous specimens of the fossil species E. Maclurii that have been examined.

To the statement that it is free, should be added the qualification "in the adult form". If the majority of individuals are formed by marginal gemmation, then they are of course attached in the younger stages. -

The juvenile specimen obtained by the Siboga Expedition was attached at the base to a foreign substance, as were also the young forms of the fossil Endopachys Maclurii formerly called Rhectopsammia claibornensis (VAUGHAN, 1900 and 1903).

In all the adult forms of $E$. Grayi I have examined, however, the disc of attachment is healed over and there can be no doubt that they were technically free.

The fan-shaped outline of the genus is a very characteristic feature. The two specimens from the Persian Gulf were sent to me in a box with other corals and among them about twenty specimens of Flabellum rubrum. The form and size of these corals were so much alike that, on the first inspection, I thought the Endopachys was an old and water-worn Flabellum. The clear and elaborate perforation of the septa and thecal wall, however, which can be clearly seen with a simple lens, and the characteristic arrangement of the septa (Fig. 2), proved that the specimens must be relegated to the Family Eupsammiidae.

The measurements of four specimens of Endopachys Grayi are given below.

A. is the specimen from the Persian Gulf now in the British Museum. B. is the second specimen from the Persian Gulf now in the Manchester Museum. C. is the Darbishire specimen. D. is the type specimen in the British Museum.

H. represents the greatest height from the base to the lip of the calyx. W. the greater diameter of the calyx and B. the lesser diameter of the calyx.

Wherever it has been found necessary to estimate a measurement owing to the specimen being broken, an asterisk is placed against the number.

$\begin{array}{lllll} & \text { A. } & \text { B. } & \text { C. } & \text { D. } \\ \text { H. } 30 \mathrm{~mm} . & 26 & 26 & 30 \\ \text { W. } 30^{*} & 26 & 26^{*} & 38 \\ \text { B. } 15^{*} & 17 & 18 & 22\end{array}$

The measurements of $D$. are copied from MiLnE EDwards and Haime.

The ratio of the two axes of the calyx is given by the French authors as a specific character, $100: 170$.

The ratio in A. B. and C. respectively are $100: 200,100: 158$, and $100: 145$.

It is probably that these ratios are of very little systematic value. The Researches of Vaughan (1900) have shown that Endopachys Maclurii is a variable species and it is highly probable that $E$. Grayi is the same, at any rate as regards such characters as the ratio of the axes of the calyx.

The external surface of the coral is marked by a series of costal ridges corresponding in number with the septa near the margin of the calyx. At the base the coral is so water-worn that it is difficult to determine with any certainty the manner in which the costae fuse, but it is quite clear that some fusion takes place.

The costae are all alike, that is to say, there is no difference to be observed between the costae corresponding with the different cycles of septa. The costae are granular in appearance, which means that the ridge is provided with small tubercles arranged in a single row half way from the base and in two or more irregular rows as they approach the margin.

In Endopachys Maclurii, there are "on the faces, two strong elevated tubercles" (VAuGHAN). These "tubercles" or as I should prefer to call them, "enlarged costal ridges" are well shown in 
Fig. 1. Plate 1, of the memoir on the "Eupsammides" by Milne Edwards and Haime, as "well as in VAUGHAN's plates. In some specimens there are two smaller enlarged ridges in addition to the primary ones.

There is no trace of any of these enlarged costal ridges in any of the four specimens of Endopachys Grayi, except in the Darbishire specimen in which 4 costae are slighty larger than the others, and so far as one can judge at present, the presence of these ridges appears to be a constant and useful character for distinguishing $E$. Maclurii from E. Grayi.

The two projecting wing-like ridges at the edges of the coral which must be regarded as the exaggerated directive costae are well developed in the species but they contract towards the base. In Endopachys Maclurii on the other hand, they expand towards the base. This difference between the two species may be expressed by the general statement that, whereas Endopachys Grayi is fan-shaped a better term for Endopachys Maclurii would be wedge-shaped.

The columella of Endopachys has been described as follows: "peu développée, spongieuse": (Milne Edwards and Haime), and "very vesiculate, elongated in the transverse axis of the calice" (VAUGHAN).

The columella in the specimen B from the Persian Gulf can be seen in the depths of the calyx to consist of a number of irregular branching trabeculae, connecting the free edges of the septa. The vertical distance from the columella to the level of the margin of the calyx in the line of the shorter axis of one of our specimens is $12 \mathrm{~mm}$. In other words the columella rises from the base to a height a little over half the distance between the base and the margin of the calyx. The greatest breadth of the columella in the same specimen is only $1 \mathrm{~mm}$.

The septa of Endopachys Grayi exhibit a very characteristic arrangement. (Fig. 2). There are 12 large septa that pass from the thecal wall to the columella, there are 12 smaller septa which do not extend quite so far into the calyx above as the larger ones but nevertheless pass into the columella below. There are 24 thin septa that pass to the columella but are joined in their course by a similar number of smaller septa and finally there are 24 smaller septa in the chambers enclosed by the last named septa. The sum total of the septa, therefore, is 96 .

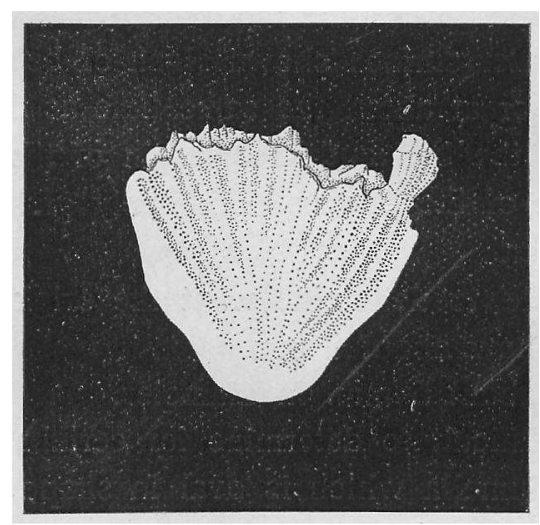

Fig. 1. Endopachys Grayi with marginal bud.

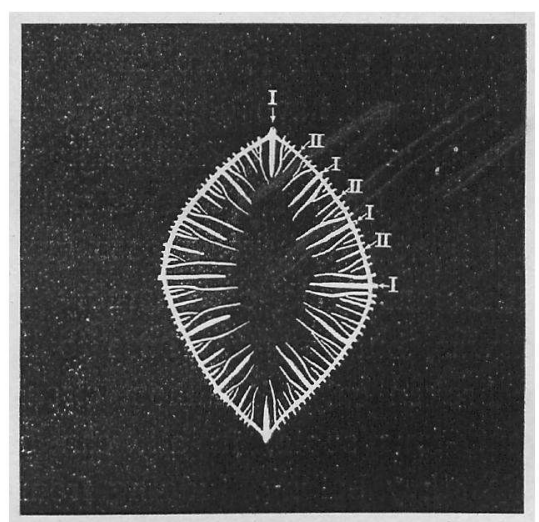

Fig. 2. Transverse section of Endopachys Grayi. I Primary \& Secondary septa. II. Tertiary septa.

The natural arrangement of these septa in Endopachys Grayi would be into five cycles. (Fig. 2):

$$
\begin{array}{ll}
\text { 1st. cycle } & 12 . \\
\text { 2nd. } ~ & 12 . \\
\text { 3rd. } ~ & 24 . \\
\text { 4th. } & 24 . \\
\text { 5th. } & 24 .
\end{array}
$$

If we wish, however, to compare the septa of Endopachys with the septa of other Eupsammiidae, it is more convenient to divide the primary cycle into two cycles.

If we regard the two directive septa and every other alternate large septum on the same side as belonging to the true primary cycle we get the six primary septa of the Eupsammiid series, the other six large septa must then be regarded as belonging to the secondary cycle. 
The septa on this system would be represented as follows:

$$
\begin{array}{lcr}
\text { 1st. cycle } & 6 . \\
\text { 2nd. } & 6 . \\
\text { 3rd. } & 12 \text {. } \\
\text { 4th. } & 24 . \\
\text { 5th. } & 24 . \\
6 \text { th. } & 24 .
\end{array}
$$

For the sake of convenience I have adopted this system.

According to this system the primaries, secondaries, tertiaries and quaternaries reach the columella, the quinaries meet and fuse with the quaternaries and the sextinaries are free above but may fuse with the septa of one of the other cycles below.

This latter point cannot at present be determined as I do not feel disposed to break up the specimens at my command.

The surfaces of the septa are for the greater part free but covered with minute tubercles. In some cases I have observed synapticulae connecting the septa. of the 6 th. cycle with those of the $5^{\text {th. }}$ close to the free edge of the former.

This statement of the septal arrangement of Endopachys Grayi cannot unfortunately be used for comparison with the septal arrangement of the other two species. The figure of Endopachys Maclurii given by MILNE EDWARDS and HAIME is taken from a level below the columella, and in VAUGHAN's account of Endopachys oahense in which he says "there are four complete cycles with members of a fifth in 13 quarter systems", it is not clear whether he takes six septa as constituting the first cycle as apparently he does in the lettering of his figure for Endopachys schaleri, or 12 septa as he does in his description of Rhectopsammia $=$ Endopachys maclurii juv.

The little marginal bud on one of the specimens (Fig. 1) is a feature of special interest as it is, so far as I am aware, the only example of gemmation known in the genus.

... I feel certain that it is a genuine case of gemmation and not a case of a young coral that has settled down and become fixed to an old dead one. The evidence is conclusive that the bud as well as the parent form, was dead at the time of capture. It has three little bits of Polytrema attached to the margin, the calyx is broken to some extent and the outer surface shows signs of being waterworn. The bud must have died, therefore, at the same time or at about the same time as the parent. There is no clear line of demarcation between the base of the bud and the margin of the calyx of the parent. It is true that the general texture of the surface of the bud is more finely granular than that of the parent but the two pass gradually into one another.

As the margin is considerably broken it is impossible to determine what the original height of the bud was, but from the base to the broken edge it is now about $6 \mathrm{~mm}$.

The broken calyx is almost circular in outline and is about $5 \mathrm{~mm}$. in diameter.

Twenty-four septa, in all, can be counted but it is difficult to determine for certain to which of the cycles they belong. Judging from the shape of the columella which is oval in shape, it seems clear that the long axis of the calyx (if complete) of the bud, would be in the same plane as the long axis of the parent.

The mere record of the occurrence of the genus Endopachys in the Persian Gulf may not seem to be a matter of much importance in itself, but when associated with other facts that have recently come to our knowledge it may be taken as a pretext for some further comments on the fauna of this interesting sea area.

Our knowledge of the marine fauna of the Persian Gulf is almost entirely based on the collections made by Mr. F. W. TownsEnd, who was engaged in the Indo-European Telegraph service from 1893-1906 and took the opportunity of collecting specimens attached to the telegraphic cable and of dredging independently with the means at his disposal.

The examination of Mr. TownSEND's collections has shown that although a very large number of the genera and species of the Persian Gulf are, as might be expected, Indian Ocean forms, there are several species whose presence has an important bearing on questions of geographical distribution.

The Mollusca, for example, show a remarkable generic analogy with the mollusca of the 
Mediterranean Sea (1907), one of the Nudibranchiata, Thecacera maculata (Eliot. 1905), appears to be identical with a British species, two species of Brachiopoda, Terebratulina caput-serpentis and Mühlfeldia truncata (1921), are common to the Mediterranean Sea and the Persian Gulf and the remarkable octoradiate coral Pyrophyllia (1911), may also indicate, through its supposed affinity with Guynia annulata, mediterranean relationship.

The occurrence of the perforate Turbinoliid coral, Trematotrochus zealandiae, which is identical with a species living off the coast of New Zealand and closely related to other species that are only found in the Tertiary deposits of Australia, raises another interesting question of geographical distribution as Pyrophyllia seems to be related to the octoradiate genus Conosmilia, which is also found only in the tertiary deposits of Australia.

Although our knowledge of the distribution of recent specimens of Endopachys is still very imperfect, these are two points that seem to be established. It is obviously very rare, only a dozen specimens having been recorded from all parts of the world, and it is widely distributed, with probably a very well marked discontinuous distribution.

Associated with these features of its recent distribution is the fact that it was extraordinarily aburidant in American tertiary deposits.

It may be inferred, therefore, that Endopachys is a relict coral, a genus that is passing from the category of recent to that of extinct corals but still maintains a struggle for existence in some of the warmer seas, such as the Gulf of California, the Persian Gulf and the Malay Archipelago.

The discovery in the Persian Gulf of the three genera of corals Endopachys, Trematotrochus and Pyrophyllia, which present so many features of special interest, by the simple methods and appliances at the disposal of Mr. TownSEND, suggests that a more thorough investigation of this area by a well-equipped national exploring vessel such as the Challenger, the Siboga, or the Valdivia might lead to the discovery of other interesting forms of animal life that are passing from the recent to the extinct.

The remarkably rich and varied marine fauna of the Malay Archipelago revealed by the Siboga expedition under the scientific direction of our distinguished friend Professor MAX WEBER, may be rivalled only by that of the Persian Gulf. In both of these sea areas we have the conditions of very warm surface waters which are undisturbed by the welling up of such cold abysmal waters as we have on the coasts of the great open oceans. Moreover the conditions of the Persian Gulf as a triangular sea area guarded on two sides by land may lead to the preservation of a fauna which under other conditions would have long ago become extinct.

For these reasons therefore I take this opportunity of calling attention to the special interest of the Persian Gulf in the hope that the next National Scientific Expedition may be induced to undertake a further exploration of the area.

Before concluding this paper $I$ should like to call attention to another point of interest in connexion with the genus Endopachys.

In the collection of corals, which included the two specimens of Endopachys, there was a series of specimens of Flabellum rubrum. These two corals belong to widely separated families of the Madreporaria and yet exhibit some features in common. Endopachys is a perforate coral and exhibits an arrangement of the septa which may be called typically Eupsammiid in character. Flabellum is an imperforate coral with septa that are typically Turbinoliid in character.

But both these corals are solitary and when adult, are free. They are both wedge or fan shaped in side view and oval or biconvex in transverse seetion and they exhibit very variable wing-like expansions of the directive costae. Moreover they both begin life in the form of conical corals, circular in transverse section, with an expanded base for attachment to a foreign substance from which they become detached after reaching a certain size. Although we have no precise information at present as to the mode of life of these corals in their natural surroundings, it seems probable that some of these characters by which they resemble one another should be regarded as special adaptations for the life of a solitary coral on a shelly or gravelly sea-bottom, i. e. on a sea-bottom that does not provide rocks or stones of suffiçient weight to support the coral when it reaches its full size.

There can be no doubt that such resemblances are not due to genetic affinity but must be 
regarded as examples of the Principle of Convergence. It is an interesting fact that in the same locality we find another example of convergence among corals due to the same necessity of maintenance of life on a shelly sea-bottom. This is the case of the Turbinoliid coral Heterocyathus and the Eupsammiid coral Heteropsammia. They are both solitary corals, although the Heteropsammia sometimes divides by fission to form two or three calices; but as they have adopted the same habit of association with a Sipunculid worm in order to maintain an upright position on a sandy or gravelly seabottom, they both exhibit the sipunculid hole at the base and assume very much the same form and appearance. In this case it is not the convergence in form that is so remarkable, for both corals are very variable in this respect, but the convergence in habit. In my collection of material from the Persian Gulf I have found a very small shell of a species of the gasteropod Cerithium to which a young Heterocyathus had become attached, just as the sea anemone Adamsia settles down on the shell of a hermit crab. If the shell contained a Sipunculid worm at the time it was caught, the coral would have gradually enveloped the shell, leaving only a tunnel through which the worm could extend itself or retreat for shelter, and thus the mutual arrangement would have been established. It is not necessary to give further details of these cases of mutualism as they are already well known by the researches of Bouvier, Stanley Gardiner, G. C. Bourne and others. My only object in referring to them here is to call attention to the second case of convergence in corals that is found within this area of the Persian Gulf.

\section{LITERATURE}

1845. LONSDAlE, W., Q. J. Geol. Soc. Vol. 1.

1848. Milne Edwards \& Haime., Ann. Sci. Nat. (3). X.

1805. Bouvier, E. L., Ann. Sci. Nat. (7). XX.

1900. Vaughan, T. W., U. S. Geol. Survey. XXXIX.

1903. Vaughan, T. W., Proc. Biol. Soc. Washington. XVI.

1904. Gardiner, J. S., Marine Investigations in S. Africa. III.

1905. Bourne, G. C., Pearl Oyster Fisheries Report. Suppl. XXIX.

1905. Eliot, SIR C., Journ. Conchol. XI.

1907. Melvill, J. C. \& Standen, R., Proc. Zool. Soc.

1911. Harrison, R. \& Hickson, S. J., Proc. Zool. Soc.

1921. Jackson, W., Ann. Nat. Hist. (9). VII. 